\title{
Anne Babalık Bilgi Testi: Geçerlilik ve Güvenilirlik Çalışması
}

\author{
DOI: 10.26466/opus.594747
}

\author{
$\underline{\text { Halis Özerk* }}$ \\ *Dr. Öğr. Üyesi, Arel Üniversitesi Sosyal Bilimler Enstitüsü/Sefaköy/İstanbul/Türkiye \\ E-Posta: halisozerk@halisozerk.com O ORCID: 0000-0001-5530-6638
}

\section{Öz}

Çalışmanın amacı anne baba tutumlarının gerisindeki bilgi türlerini ve düzeylerini belirleyebilecek bir ölçek geliştirmek ve ölçeğin geçerlilik ve güvenilirlik çalışmasını yapmaktır. Anne Babalık Bilgi Testi (ABBT) do$\breve{g} u m$ öncesi, bebeklik, çocukluk ve ergenlik olmak üzere 4 temel kategoriye ayrılmış ve madde havuzu içerisinden bu kategorilere ait toplam 100 ifade seçilmiştir. Bu ifadeler, uzmanlarla birlikte değerlendirilmiş, bazı ifadeler elenmiş bazı ifadelerde değiş̧iklik yapılmış ve toplam 70 ifadeden (maddeden) oluşan ölçek deneme formu hazırlanmıştır. Ana-babalar tarafından, ölçekte "doğru" veya "yanlış" şeklinde yanıtlanması istenen bilgilerin bilimsel temellere dayalı net bilgiler olmasına özen gösterilmiştir. Toplam 70 maddeden oluşan ve yönergesi de hazırlanan ABBT deneme formu, geçerlilik ve faktör analizi çalışması için araştırma grubuna (45' i erkek, 65' i kadın olmak üzere toplam 110 ana-babaya) uygulanmıştır. Maddeler arası tetrakorik korelasyon katsayıları Statistica 4.5 programı aracılığı ile hesaplanmış ve tetrakorik korelasyonlara dayanan temel bileşenler analizi (faktör analizi) yapılmışıı. Analiz sonucunda bazı maddelerin iki faktörde birden yer aldı̆̆ görülmüş ve faktör yapısın düzenlemek amacıyla varimax rotasyonu uygulanmıştır. Uygulanan rotasyon sonucunda ölçeğin maddelerinin üç temel faktörde (boyutta) toplandığı gözlenmiştir. ABBT' nin faktör analiziyle belirlenen üç faktörüne, maddelerin (ifadelerin) özellikleri dikkate alınarak; I. Faktör' e "Geleneksel Bilgi", II. Faktör' e "Magazinsel Bilgi", III. Faktör' e ise "Bilimsel Bilgi" adları verilmiştir. Yinelenen rotasyonlu faktör analizi sonucunda nihai ölçeğe ulaşılmıştır. Nihai ölçek 47 maddeden oluşmuştur. ABBT" nin ayırdedicilik özelliğini görebilmek için deney ve kontrol gruplarn oluşturulmuştur. Ölçek, deney ve kontrol grubuna 21 gün ara ile iki kez uygulanarak, test-tekrar test yöntemiyle; deney ve kontrol gruplarının kendi içlerindeki değişimleri gözleyebilmek amacıyla ön test ve son test puanları tekrarl ölçümler için $t$ testi ile karşılaştırılmıştır. Deney ve kontrol gruplarının sontest puanları ortalamaları arasında istatistiksel olarak anlamlı bir fark bulunmaktadır. Buna göre ölçek, deney ve kontrol gruplarını son test puanlarına bağlı olarak ayırt edebilmektedir ( $t=-36,90 ; p<0,01)$. Bu maddelerden oluşan nihai ölçeğin güvenilirlik katsayısı da (KR-20 güvenilirlik katsayısı) 0,93 olarak bulunmuştur. Öyle görünmektedir ki ölçek bu haliyle çok yüksek bir iç tutarlllı göstermektedir. Bu anlamıyla da güvenilirliği oldukça yüksektir. Sonuç olarak, ABBT' nin kabul edilir psikometrik özelliklere sahip olduğu, araştırma ve uygulamalarda kullamılabilir olduğu görülmüştür.

Anahtar Kelimeler: Anne Babalık, Bilgi/Bilinç Testi, Test 


\title{
Parenting Knowledge Test: Validity and Reliability Study
}

\begin{abstract}
The purpose of this study was to develop a scale that can determine the types and levels of knowledge behind parents' attitudes; performing the validity and reliability studies of the related scale was the goal as well. Parenting Knowledge Test (PKT) is divided into 4 main categories in principle as prenatal, babyhood, childhood and puberty; entirely 100 expressions were selected from the item pool belongs to these categories. Scale trial form that consists of 70 expressions was prepared by evaluating the expressions with professionals; eliminating some expressions and also emending in some of the expressions. It was especially paid attention to information that was asked to parents to answer to be certain information based on a scientific basis. PAKT trial form whose guideline was also already prepared was applied in the research group (entirely 110 parents whose 45 were males and 65 were females) for validity, reliability and factor analysis study. Statistical 4.5 program computed tetrachoric correlation coefficients among the items; principal component analysis (factor analysis) based on tetrachoric correlations was conducted. It was seen at the end of the analysis that some of the items placed in both two factors at the same time; varimax rotation was performed to organize the factor structure. We observed as the result of related rotation that items of the scale are gathered on three key factors (dimensions). These three key factors that were specified by factor analysis of PAKT have been entitled as follows; The 1st factor is "Traditional Knowledge", The 2nd factor is "Magazinish Knowledge", The 3rd factor is "Scientific Knowledge". The final scale has been reached at the end of repeated factor analysis with rotation. The final scale is composed of 47 items. Experimental and control groups were established to see the distinctiveness feature of PAKT. The scale was applied in the experimental and control group for two times by a 21days gap. Pretest and posttest scores were compared by $t$-test for repetitive measures on the purpose of observing the transformations in experimental and control groups in themselves. There is a statistically significant difference between posttest point averages of experimental and control groups. For this finding, the scale can distinguish the experimental and control groups based on the posttest scores $(t=-36,90 ; p<0,01)$. The reliability coefficient (KR-20-reliability coefficient) of the final scale with these items was calculated as 0,93. It would appear that this scale, as is, shows a so high internal consistency; accordingly, its reliability is pretty high as well. In conclusion, PAKT has reasonable psychometric attributes; it can be used in research and applications.
\end{abstract}

Keywords: Parenting, Knowledge/consciousness Test, Test 


\section{Giriş}

Filozoflar, çocukluğun oluşturucu doğası hakkında fikir yürüttüler; ahlakçılar, çocukların davranışı hakkında açıklamalar yaptılar; ana-babalar çocuklarının gelişmelerini anlamak istediler. Ancak, yaklaşık yüzyıl öncesine kadar çocukların bilimsel olarak incelenmesi gerçek anlamda ortaya çıkmış değildi. Sistemli araştırmalar, çocuğun ve ergenin gelişiminin büyüleyici öyküsünü anlamak için kullanabileceğimiz bir bilgi birikimine yol gösterdiler. Örneğin orta çağda, yaklaşık olarak 5. ve 13. yüzyıllar arasında, insanlar çocukluğu yaşamın farklı bir dönemi olarak görmüyordu. Bildiğimiz resmi eğitim kavramı mevcut değildi ve bunun sonucu olarak çoğu çocuk için okul da yoktu. Bunun yerine çıraklık hemen hemen eğitimin evrensel biçimini oluşturmaktaydı. 1600' lere gelindiğinde çocukluğu yetişkinlikten farklı olarak görmeye başladılar. (Gander and Gardiner, 1981; çev: Ali Dönmez, Nilgün Çelen ve Bekir Onur,1993, s.27-30,31).

İnsan davranışının ve kişilik özelliklerinin incelenmesiyle birlikte, bebeklik, çocukluk ve ergenlik dönemlerinde ana-babaların tutumları da ele alınmaya ve bireyin davranışları ile ilişkilendirilmeye çalışılması günümüze kadar devam etmiştir.

Psikanalitik kuramın kurucusu Freud, çocukluk dönemlerindeki, anababa tutumlarının bireyin kişilik gelişimi ve davranışları açısından büyük önem taşıdığını ifade etmektedir. Hatta ana-babaların hatalı tutumları nedeniyle bu dönemlerden herhangi birine saplanmanın bireyin kişilik özelliklerini belirleyebileceğini ileri sürmüşür (Öztürk,1989, s.62; Geçtan, 1993, s.43; Cüceloğlu, 1998, s.412,413). Psikanalitik kuramın devamcıları olarak bilinen Adler de Jung' da yaşamın ilk yıllarındaki anne baba tutumlarının çocukların gelecekteki yaşamında büyük önem taşıdığı konusunda hemfikir olmuşlardır.

Bağlanma kuramının öncüleri sayılan Bowlby, Ainsworth, Klein ve Harlow da gerek gözlemlerine gerekse yaptıkları deneylere dayalı olarak; annenin, bebeği ile bebeklik dönemindeki iletişim biçiminin, temel ihtiyaçlarını karşılama biçiminin, temasının, sıcak ilgisinin, o dönemde bebekten ayrı kalmamasının önemine vurgu yapmışlar ve bu davranışların olumlu ya da olumsuz özellikler taşımasına bağlı olarak çocukta güvenli ya da problemli bağlanma durumlarının ortaya çıkabileceğini belirtmişlerdir (Ainsworth, 1985, 1989; Ainsworth an Bell, 1970; Aikins, Howes and 
Halilton, 2009; Carver,1998, s.281-282; Brown and Wright, 2003; Robinson and Moss, 1970; Sevinç, 2016).

Günümüzde, özellikle gelişmiş toplumlarda gerek psikiyatristleri gerek psikologları gerek eğitimcileri ve gerekse toplumbilimcileri çocuklar, gençler ana-babalar ve gelecek kuşaklar bakımından endişelendiren durumlar (zararlı madde kullanımında, kapkaç olaylarında, suç işleme davranışlarında ve bu konulardaki yaş düzeyinin gittikçe düşmesindeki artış vb.) yaşanmaktadır. Bu nedenlerle toplumların daha sağlıklı bireylerden oluşturulması amacıyla bireylerin ruh sağlığını koruma ve sağlıksız davranışların nedenlerini önlemeye yönelik çabalar her geçen gün artmaktadır. Çünkü problemlerin oluşmasını önleme çalışmaları, oluştuktan sonra giderme çalışmalarından daha akıllıca, daha sağlıklı, daha kolay ve üstelik daha ekonomiktir. Önleme ve koruma çalışmalarında temel amaç, sağlıklı toplumlar ve sağlıklı bireyler oluşturmak olduğuna göre, ağırlık verilmesi gereken çalışmaların da toplumların en küçük ve en temel birimi olan ailelerden (yani ana-babalardan) başlatılması gereği açıktır. Ana-babalara yönelik çalışmaların ise, hatalı değer yargılarının, çocuk yetiştirme konusundaki sağlıksız ve olumsuz ana ana-baba tutumlarının olumlu yönde geliştirilmesi çerçevesinde yürütülmesi ihtiyacı vardır. Çünkü bireyin temel davranış örüntülerinin ve kişilik özelliklerinin ağırlıklı olarak aile ortamında oluştuğu kabul edilmektedir.

Kauffman (1997), tüm kültürlerin çocuğun kişiliğinin gelişmesinde ve öğrenim yaşantılarında aileye temel rolü ve sorumluluğu verdiğini ve yetişkin yaşama kadar da bu sorumluluğun ailede olduğunu belirtmektedir.

Bireylerin -olumlu veya olumsuz-, kişiliklerinin oluşumunda, temel alışkanlıkları kazanmalarında, bazı davranış biçimleri oluşturmalarında, tavırlarında ve değer yargıları geliştirmelerinde çocukluk çağının hatta ilk çocukluk çağının önemi bilinmektedir.

Belsky, Sligo, Jaffee, Woodward ve Silva (2005) tarafından yapılan çalışmada, annelerin çocuklarını yetiştirme tarzları ile kendi yetiştirilme tarzları arasında anlamlı bir ilişki bulunmuştur.

Bununla ilintili olarak, özellikle ülkemizde yapılan çalışmalar, anne babaların çocuklarıyla ilgili birçok konuda kendilerini yetersiz olarak algıladıkları ve sıklıkla zorluk yaşadıklarını ortaya koymaktadır (Ulusavaş, 1988; Atakl1, 1999). 
Hassoy ve Çakıcı (2012), davranış bozukluğu gösteren çocuğa sahip ailelerle yaptıkları çalışmada, ailelerin çocuklarında görülen davranış bozuklukları (tikler, dikkat eksikliği ve hiperaktivite, yalan söyleme, altını ıslatma, okul fobisi, kekemelik, psikosomatik bozukluklar, saldırganlık) hakkında yeterli bilgiye sahip olmadıklarını, bu nedenle normal davranış ile bozukluğu ayırt edemediklerini, buna bağlı olarak da sağlıksız tutumlar gösterdiklerini bulgulamışlardır.

Araştırmacılar tutum değişikliğine gidilirken tutumun gücünü dikkate almanın gerektiğini belirtmektedirler. Araştırmacılara göre her tutumun bir gücü (şiddeti) vardır. Bu güç, tutumun bütün ögelerinin gücünün toplamı olabilir. Böyle durumlarda o tutumun değiştirilmesi çok zor olacaktır. Araştırmacıların bu noktada sordukları önemli bir soru şudur: Tutum nesnesi ile doğrudan bir yaşantı sonucu edinilen (oluşan) tutumlar mı yoksa doğrudan yaşantılarla edinilmemiş (oluşmamış) tutumlar mı davranışı daha fazla belirlemektedir? Bu araştırmacılardan Fazio ve Zanna, doğrudan yaşanarak kazanılmış tutumların daha güçlü olduğunu ve zor değiştirilebileceğini, doğrudan yaşantılarla edinilmemiş ama öğrenilmiş olan tutumların ise ikna yoluyla daha kolay değiştirilebileceğini belirtmektedirler (Arkanoç, 2005, s.34-36).

Öyleyse çocuklarda görülen davranış problemlerini olumlu yönde değiştirebilmek için bu davranışların temel nedenlerinden biri olarak açıklanan ana-baba tutumlarını değiştirebilmek üzerinde bilimsel bilgilerle ve ikna edici şekilde çalışmak gerektiğini söylemek de hatalı olmayacaktır.

Kazdin (1987)' e göre, ana-baba ve çocuk arasındaki sağlıksız etkileşimler sonucu ortaya çıkan çocuktaki olumsuz davranışların giderilmesi ile ilgili çalışmalara bakıldığı zaman karşımıza şu sonuç çıkmaktadır: Sonuçlandırmaya dayalı uzun davranış tedavileri 1 veya 2 yıl içinde etkilerini kaybetmektedirler. Bu nedenle en iyisi, kısa süreli etkileri olacak eğitimler üretmektir. Bunun için de en yararlısı kısa süreli, ergenlik öncesi ve ergenlik dönemine ilişkin bilgilerin verildiği aile eğitimleridir.

Nilsson (2016), madde bağımlılığı olan, dürtü kontrolsüzlüğü olan 1217 yaş arası ergenlere sahip ailelerle yaptığı çalışmada, anne babaların gerek dönemlerine ilişkin gerekse çocuklarının aktivitelerine ilişkin bilgi sahibi olmaları ile çocuklarının sözü edilen bozukluklar arasında anlamlı bir ilişki bulgulamıştır. 
Navaei ve ark. (2018), istismara maruz kalan 2-6 yaş arası çocuğa sahip ailelerle yaptıkları çalışmada, anne babaların çocuğun gelişimsel özellikleri başta olmak üzere, istismara uğramış çocuğa ilişkin davranışları hakkında bilgi sahibi olmanın da çocuklarına yönelik tutum ve çocuklarıyla etkin iletişim becerileri konusunda öz yeterliliğe sahip olabileceklerini ifade etmektedirler.

Arkan ve Üstün (2009) davranım bozukluğu olan çocukların ebeveynlerine yönelik gerçekleştirdikleri eğitim programı sonunda, çocukların davranışlarında olumlu yönde değişimler görüldüğünü ifade etmişlerdir.

Ay ve Şahan (2018) anne babalara yönelik düzenledikleri Aile Eğitimi programı sonunda, anne babaların çocuklarıyla iletişimlerinin daha sağlıklı hale geldiğini, çocuklarının akademik başarılarının arttı̆̆ını, aile içi şiddet davranışında anlamlı düzeyde azalma görüldüğünü belirtmişlerdir.

Çekiç, Akbaş ve Hamamcı (2016), anne babaların akılcı olmayan inançları ve anne babalık stresi olarak tanımladıkları duygu durumlarının düzenlenmesi amacıyla yürüttükleri yedi haftalık eğitim programı sonunda hem deneysel işlem sürecinde hem de üç aylık izleme dönemi sonunda, deney grubunda yer alan anne babaların stres düzeylerinin düştüğünü, akılcı olmayan inançlarının azaldığını göstermişlerdir.

Nasıl ki gelişim psikolojisine göre, bebeklikten çocukluğa, çocukluktan ergenliğe ve ergenlik dönemi sonuna kadar, bir dönemin sağlıklılığ bir önceki dönemin sağlıklılığına bağlı ise, ana-babalığın sağlıklılığının da bir önceki dönem olan ana-baba adaylığına ilk adımın atıldığı döneme, yani döllenmenin gerçekleştiği dönemdeki ana-baba adaylarının bilinçlilik düzeyine (hatta döllenme öncesi yapılması gerekenlerle ilgili bilinçlilik düzeyine) bağlı olabileceğini söylemek hatalı olmayacaktır.

Bilinçlilik düzeyi ile kastedilen; ilgili alan uzmanlarınca (örneğin Kadın Sağlığı, Hastalıkları ve Doğum Uzmanı, Çocuk Sağlığı ve Hastalıkları Uzmanı, Beslenme ve Diyetetik Uzmanı, Çocuk ve Ergen Psikiyatristi, Diş Hekimi, Çocuk Psikoloğu, Ergen Psikoloğu, Klinik Psikolog) ana-baba adaylarının ve ana-babaların hamilelik, bebeklik, çocukluk ve ergenlik dönemlerine ilişkin temel olarak bilmelerinin gerekli ve yeterli olduğu düşünülen bilgi düzeyleridir.

Gerek ulusal gerekse uluslararası alan yazında, çocuk ve ergenlerde görülen davranış bozuklukları, psikolojik problemler, akademik başarı, 
benlik saygısı, girişkenlik, problem çözme becerileri vb. özellikler ile anne baba tutumları arasındaki ilişkiye bakılan çalışmaların yoğun olduğu görülmektedir. Bu çalışmaların büyük bir çoğunluğunda da anlamlı ilişkilere ilişkin bulgulara yer verildiği görülmektedir. Tutum ve tutum değişiminin ağırlıklı olarak ele alındığı sosyal psikoloji alanında ise tutumların, düşünce, duygu ve davranış olmak üzere üç temel bileşeni olduğu, tutum değişimini asıl belirleyen unsurun ise düşünce yani kognitif (bilişsel) yapıda var olan bilgi repartuarı olduğu vurgulanmaktadır (Kağıtçıbaşı, 2003;108). Dolayısıyla tutumların değiştirilebilmesi için ilk adım, bireyin bilişsel yapısındaki bilgilerin ne olduğunun bilinmesidir. Sonrasında ise arzu edilen tutumların gerçekleştirilebilmesi için ne tür yeni bilgilerin bireye sunulması gerektiğidir.

Çalışmanın amacı, sağlıksız anne baba tutumlarının gerisindeki bilgi ya da bilgilerin neler olduğunu ortaya koyabilecek ve yapılacak çalışmayı planlamaya yardımcı olacak, geçerliliği ve güvenilirliği olan bir ölçek geliştirebilmektir.

Geliştirilen ABBT (Ana-babalık Bilg Testi)' nin bilimsel araştırmalarda ya da uygulamalı çalışmalarda kullanılmasıyla, sonuçlara dayalı sağlıklı ana-baba tutumlarının oluşmasına ve daha bilimsel ana-babalık bilgilerine sahip ana-babaların sayısını artırmasına katkıda bulunulabileceği düşünülmektedir. Ayrıca geliştirilen ABBT ile ana-babaların, ana-babalık bilgi düzeyi' ni belirlemek olası olabilecektir ki bu da ana-babalara yönelik çalışmalarda hangi alana ağırlık verileceğinin belirlenmesi bakımından büyük yarar sağlayabileceği düşünülmektedir.

Bununla birlikte ana-baba tutumları ile ilgili olarak ülkemizde yapılan araştırmaların hemen hemen tamamında, süreç (tutumların oluşumundaki bilgilenme süreci) değil sonuç (tutumlar) ele alındığ için literatürde "Anne Babalık Bilgisi" ne (ya da Anne Babalık Bilinçliliği) ne ilişkin herhangi bir çalışmaya rastlanmamıştır. Yani, anne - babaların çocuk yetiştirmeye ilişkin tutumlarının gerisinde yer alan ve bu tutumların ortaya konmasında en büyük rolü oynayan "Anne Babalık Bilgisi" nin ne olduğu, doğruluk veya yanlışlık bakımından hangi düzeydeki bilginin hangi tutumlarla ilişkili olduğunu inceleyen bir çalışmaya da rastlanamamıştır.

Bu bağlamda; "Anne- Babalık Bilgisi" ni ölçmeye yönelik olarak ülkemizde halihazırda kullanılan herhangi bir ölçeğe de rastlanmamıştır (Öner,2009). 


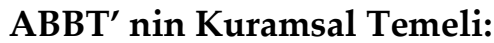

ABB (Ana-babalık Bilgisi) kavramı, ana-baba tutumları kuramcılarından ve ana-baba tutumlarını inceleyen araştırmacılardan esinlenerek, araştırmacı tarafından geliştirilmiş ve bu araştırmada kullanılmıştır.

Ana-babalık bilgisinin, ana-baba tutumlarıyla yakından ilişkili hatta ana-baba tutumlarını belirleyen bir kavram olduğu düşünülmektedir.

Yapılan literatür çalışmasında ana-babalık bilgisi ile ilgili olarak iki çalışmaya ulaşılabilmiştir. Bunlardan birincisi Gullo (1988) tarafından gerçekleştirilmiştir. Gullo, çalışmasında yaşları ortalama 16.8 olan 20 ergen anne ile yetişkin yaşta (yaş ortalamaları 30) olan 20 annenin (toplam 40 annenin) 0-14 aylık bebeklerin motor, sosyal, bilişsel ve dil gelişimine ilişkin bilgilerinin düzeyini karşılaştırmıştır. Ergen anneler lise öğrencisi olup \%50' si beyaz, \%30' u siyah \% ve \%20' si İspanyol kökenli idi. Çocuklarının yaş ortalaması ise 18 ay idi. Yetişkin anneler de ergen anneler gibi tek çocuğa sahip idi ve çocuklarının yaş ortalaması 13,7 ay idi. Çalışmada annelere, belirtilen gelişimsel alanları içeren 56 itemlik soru listesi verilmiş ve araştırma sonunda her iki grubun da ortalamanın altında puanlar aldıkları görülmüştür. Karşılaştırma sonuçlarında ise ergen annelerin puanı yetişkin annelere göre oldukça düşük bulunmuştur.

Lally, Lerner ve Hurvitz (2001) tarafından gerçekleştirilen diğer çalışmada ise, bebeklik ve ilk çocukluk döneminin gelişimsel özelliklerine ilişkin 3000 ana-babaya (bunların 1000' i yeni doğmuş bebek ile 6 yaş arası çocuğa sahip ailelerdi) sorular yöneltilmiştir. Ana-babaların bilgilerinin kayg1 verici düzeyde yetersiz ve üstelik hatalı olduğu görülmüştür.

Her iki çalışmada da araştırmacılar ana-babalık bilgisi konusunda çalışmaların eksik olduğunu tespit ettiklerini ve bu konunun önemine işaret ederek çalışmaların yapılması gerektiğini belirtmişlerdir.

Ülkemizdeki literatür taramasında ise ana-babalık bilgisi konusunda bir çalışmaya rastlanamamıştır.

Bu bağlamda, araştırmada ana-babaların, ana-babalık bilgi düzeylerine ilişkin veriler araştırmacı tarafından geliştirilen ABBT (Ana-babalık Bilgi Testi) aracilığı ile toplanmıştır. 


\section{YÖNTEM}

\section{ABBT (Anne Babalık Bilgi Testi)’ nin Geliştirilmesi}

$\mathrm{ABBT}^{\prime}$ nin doğum öncesinden başlayarak ergenlik dönemi sonuna kadar bireyin gelişim alanlarını, davranış özelliklerini, bu dönemlerde görülen davranış problemlerini, kişilik özelliklerine ilişkin bilgileri / yeterlilikleri içine alan bir araç olması hedeflenmiştir.

$\mathrm{Bu}$ amaçla, yukarda genel olarak sıralanan her bir kategoriye ait ifadelere yer verebilmek için literatüre dayanılarak ve uzmanlarla (Kadın Hastalıkları ve Doğum, Çocuk Sağlığı ve Hastalıkları, Beslenme ve Diyetetik ve Diş Sağlı̆̆ı alanlarında Erciyes Üniversitesi Tıp Fakültesi Öğretim Üyeleri ile) görüşülerek öncelikle madde havuzu oluşturulmuştur.

Düşünülen ABBT; doğum öncesi, bebeklik, çocukluk ve ergenlik olmak üzere 4 temel kategoriye ayrılmış ve madde havuzu içerisinden bu kategorilere ait toplam 100 ifade seçilmiştir. Bu ifadeler, kategorilerle ilgili uzmanlarla birlikte değerlendirilmiş, bazı ifadeler elenmiş (örneğin birbirine yakın ifadeler), bazı ifadelerde değişiklik yapılmış ve toplam 70 ifadeden (maddeden) oluşan ölçek deneme formu hazırlanmıştır.

Ana-babalar tarafından, ölçekte "doğru - yanlış" şeklinde yanıtlanması istenen net bilgilerin, daha çok bebeklik ve çocuklukta yer aldığı gerçeği hem uzmanlar tarafından dile getirilmiş hem de literatürde bu gerçek görülmüş ve her bir kategorideki ifadelerin birbirine yakın sayılarda olmasına özen gösterilmiştir. Toplam 70 maddeden oluşan ve yönergesi de hazırlanan ABBT deneme formu, geçerlilik ve faktör analizi çalışması için araştırma grubuna (45' i erkek, 65' i kadın olmak üzere toplam 110 anababaya) uygulanmıştır.

ABBT gerek deney ve gerekse kontrol gruplarına, küçük gruplar halinde ve araştırmacı tarafından uygulanmıştır.

Madde seçimi için maddelerin her birisi, ayırdediciliği olup olmadığını belirlemek amacıyla toplam puanla korelasyonları bakımından ve madde güçlük düzeyi bakımından hem biserial (çift serili) korelasyon katsayılarıyla hem de alt-üst grup ayırdediciliği ile incelenmiştir.

Yapılan biserial korelasyon katsayılarına dayalı madde ayırdedicilik indeksi ve alt-üst grup ayırdediciliği indeksi hesaplamaları sonucunda 
ayırdedicilik katsayıları $0.30^{\prime}$ un altında değerler alan maddeler ölçekten çıkartılmıştır.

Madde güçlük indeksine dayalı olarak ölçekten çıkartılan maddelerden sonra kalan 52 madde, ölçeğin faktör yapısını (temel boyutlarını) belirlemek amaciyla faktör analizine sokulmuştur. Maddeler arası tetrakorik korelasyon katsayıları Statistica 4.5 programı aracılığı ile hesaplanmış ve tetrakorik korelasyonlara dayanan temel bileşenler analizi (faktör analizi) yapılmıştır. Analiz sonucunda bazı maddelerin iki faktörde birden yer aldığı görülmüş ve faktör yapısını düzenlemek amaciyla varimax rotasyonu uygulanmiştır.

Uygulanan rotasyon sonucunda ölçeğin maddelerinin üç temel faktörde (boyutta) toplandığı gözlenmiştir. ABBT' nin faktör analiziyle belirlenen üç faktörüne, maddelerin (ifadelerin) özellikleri dikkate alınarak;

I. Faktör' e "Geleneksel Bilgi",

II. Faktör' e "Magazinsel Bilgi",

III. Faktör' e ise "Bilimsel Bilgi" adları verilmiştir.

Kalan maddeler (toplam 52 madde) ölçeğin faktör yapısını (temel boyutlarını) belirlemek amaciyla faktör analizine sokulmuştur.

Ölçek maddeleri Doğru =1 (bir) ve Yanlış =0 (sıfır) şeklinde puanland1ğından bu maddelere dayılı olarak yapılacak faktör analizinin tetrakorik korelasyon katsayılarına dayalı faktör analizi olması gerektiği Lord ve Novick (1968) ve Hambleton, Swaminathan ve Rogers (1991) tarafindan bildirilmiştir. Maddeler arası tetrakorik korelasyon katsayıları Statistica 4.5 programı aracılığı ile hesaplanmış ve tetrakorik korelasyonlara dayanan temel bileşenler analizi (faktör analizi) yapılmıştır. Analiz sonucunda bazı maddelerin iki faktörde birden yer aldığı görülmüş ve faktör yapısını düzenlemek amaciyla varimax rotasyonu uygulanmıştır. Uygulanan rotasyon sonucunda ölçeğin maddelerinin üç temel faktörde (boyutta) toplandığ1 gözlenmiştir.

Faktör analizine giren maddelerden de toplam 5 maddenin yeteri kadar (herhangi bir faktöre dahil olacak kadar) faktör yükü alamadığı görülmüştür. Bu 5 madde de ölçekten çıkartıldıktan sonra yinelenen rotasyonlu faktör analizi sonucunda nihai ölçeğe ulaşılmıştır.

Nihai ölçek 47 maddeden oluşmuştur. Yapılan analizler sonucunda kalan 47 maddenin faktör analizi sonuçları aşağıda tablo 1' de verilmiştir. 
Tablo 1. ABBT Faktör Analizi Sonuçları

\begin{tabular}{|c|c|c|c|}
\hline Maddeler & Faktör I & Faktör II & Faktör III \\
\hline 2 & .38119 & & \\
\hline 3 & & .580111 & \\
\hline 4 & & & .567868 \\
\hline 5 & & .515145 & \\
\hline 6 & & & .429827 \\
\hline 7 & .71052 & & \\
\hline 8 & .70454 & & \\
\hline 9 & .67611 & & \\
\hline 10 & .84892 & & \\
\hline 11 & & .467143 & \\
\hline 12 & .58488 & & \\
\hline 13 & .80628 & & \\
\hline 15 & .91935 & & \\
\hline 17 & & .751139 & \\
\hline 20 & & .321931 & \\
\hline 21 & .50232 & & \\
\hline 22 & & .475369 & \\
\hline 23 & & & .646271 \\
\hline 24 & & & .548368 \\
\hline 25 & & & .529042 \\
\hline 26 & & .344220 & \\
\hline 27 & .72430 & & \\
\hline 28 & .69144 & & \\
\hline 29 & .49207 & & \\
\hline 30 & & .745084 & \\
\hline 31 & & & .451752 \\
\hline 32 & 69815 & & \\
\hline 37 & & & .426415 \\
\hline 38 & & & .470236 \\
\hline 39 & & .507997 & \\
\hline 40 & .62510 & & \\
\hline 41 & .53530 & & \\
\hline 44 & & .526805 & \\
\hline 45 & & .808489 & \\
\hline 46 & & .478297 & \\
\hline 47 & & .403059 & \\
\hline 48 & & .535617 & \\
\hline 49 & & .515240 & \\
\hline 50 & .66316 & & \\
\hline 51 & .70270 & & \\
\hline 53 & & & .431075 \\
\hline 56 & & & .404200 \\
\hline 58 & .46484 & & \\
\hline 62 & .47193 & & \\
\hline 63 & .37205 & & \\
\hline 67 & & .889174 & \\
\hline 69 & .46073 & & \\
\hline
\end{tabular}


ABBT' nin faktör analiziyle belirlenen üç faktörüne, maddelerin (ifadelerin) özellikleri dikkate alınarak;

I. Faktör' e "Geleneksel Bilgi",

II. Faktör' e "Magazinsel Bilgi",

III. Faktör' e ise "Bilimsel Bilgi" adları verilmiştir.

I. Faktör' de;

"Hamilelikte ilk 3 ay beslenme açısından diğer dönemlerden daha etkilidir",

"Doğumunun ilk gününde anneyi emmekte zorlanan bebeğe, tatlandırılmış suya batırılmış emzik verilmelidir",

"Ateşi yüksek olan çocuğun ateşini düşürmek için terletmek yararlıdır" gibi ağırlıklı olarak kuşaktan kuşağa, kulaktan kulağa ve genellikle çocuk doğurma sayısı bakımından tecrübeli olarak görülen büyükler tarafından, kendilerince tecrübesiz genç kuşaklara aktarılan "geleneksel" ve "bilimsel bilgi" ile uyuşmayan bilgileri içeren ifadeler yer almaktadır.

II. Faktör' de;

"Hamilelikte çocuk gelişimi açısından anne adayı özellikle kalsiyum vitamini almaya ağırlık vermelidir",

"Bebeğin doğum boyunun 55-60 cm. arasında olması normaldir"

"Bebeğe 6. aydan itibaren katı besinler verilmelidir",

Çocuklara tuvalet eğitimi verilirken bezden külota ani geçiş yapılmamah, bir süre gündüzleri külot, geceleri ise bez bağlanmahdır" gibi kesin ifadelerin kullanıldığı, hatta bu konuda belli sayıların belirtildiği, bilimsel bir temele dayanmayan, verilen bilginin kaynağının belirtilmediği, sanki kesin doğru imiş gibi sunulan ve hatalı bilgi içeren ifadeler yer almaktadır.

III. Faktörde ise;

"Hamilelikte çocuğun anormal doğmaması için anne adayı özellikle folik asit almalıdır",

"Çocukluk döneminde en hızl gelişim doğumdan sonraki ilk aydır"

"Çocuğun gelişimi içten dışa, baştan aşağı doğrudur" şeklinde, ağırlıklı olarak literatüre ve uzman bilgisine dayalı bilimsel yani doğru (sağlıklı) bilgiler yer almaktadır. Dolayısıyla bu ifadeler, bilimsel bilginin özellikleriyle uyuşmaktadır. Yani; en son verilere göre ve aksi kanıtlanıncaya kadar doğru olarak kabul edilen, değişebilir olan ve kaynağı belli olan bilgi ifadeleridir.

Madde seçimi için maddelerin her birisinin ayırdediciliği olup olmad1ğını belirlemek amaciyla toplam puanla korelasyonları bakımından ve 
madde güçlük düzeyi bakımından hem biserial (çift serili) korelasyon katsayılarıyla hem de alt-üst grup ayırdediciliği ile incelenmesine ilişkin değerler Tablo 2' de gösterilmiştir.

Tablo 2. ABBT Madde Güçlük ve ayırt edicilik Değerleri Tablosu

\begin{tabular}{|c|c|c|}
\hline Soru no & Madde güçlükleri & Madde ayırtedicilikleri \\
\hline $\mathrm{s} 01$ & ,8833 &,- 118 \\
\hline s02 & 0361 & ,075 \\
\hline s03 & 6056 &,- 075 \\
\hline s04 & ,9389 & ,106 \\
\hline s05 & ,5972 & ,348 \\
\hline s06 & 6333 & ,386 \\
\hline s07 & 2694 & 157 \\
\hline s08 & 7611 & ,227 \\
\hline s09 & 6889 & ,449 \\
\hline s10 & 2083 & 147 \\
\hline s11 & 7583 & ,466 \\
\hline s12 & ,5389 & ,439 \\
\hline s13 & 2000 & ,031 \\
\hline s14 & 1667 & 267 \\
\hline s15 & ,7694 &,- 114 \\
\hline s16 & 6139 & ,063 \\
\hline s17 & 8444 & 290 \\
\hline s18 & ,8639 & 314 \\
\hline s19 & ,3722 & ,048 \\
\hline s20 & 7667 &,- 206 \\
\hline s21 & ,4861 & ,345 \\
\hline s22 & 2778 & ,315 \\
\hline s23 &, 5111 & ,464 \\
\hline s24 & 4972 & ,420 \\
\hline s25 & 6278 & ,407 \\
\hline s26 & 2528 & ,272 \\
\hline s27 & 7861 & 400 \\
\hline s28 & ,5556 & ,506 \\
\hline s29 & 6528, &,- 236 \\
\hline s30 & 5889, &,- 162 \\
\hline s31 & 1500, & 202 \\
\hline s32 & 1361 & 163 \\
\hline s33 & 1278, & 189 \\
\hline s34 & 2389, & ,063 \\
\hline
\end{tabular}




$\begin{array}{lll}\text { s35 } & , 7250 & -, 202 \\ \text { s36 } & , 6333 & , 382 \\ \text { s37 } & , 4611 & , 481 \\ \text { s38 } & , 7417 & , 079 \\ \text { s39 } & , 218 \\ \text { s40 } & , 7111 & , 077 \\ \text { s41 } & , 0472 & , 033 \\ \text { s42 } & , 9750 & -, 037 \\ \text { s43 } & , 7694 & -, 096 \\ \text { s44 } & , 7722 & , 101 \\ \text { s45 } & , 2639 & -, 258 \\ \text { s46 } & , 6528 & , 441 \\ \text { s47 } & , 5250 & -, 078\end{array}$

Faktör yapısının ölçülmeye çalışılan değişkenin ne kadarını açıkladığını belirlemek amacıyla özdeğerler (eigenvalues) incelenmiş ve her bir faktörün ölçülen değişkendeki varyansın ne kadarını açıkladığı belirtilmiştir.

Tablo 3’ de faktörlere ilişkin özdeğerler ve varyanslar (yüzde değerleriyle) yer almaktadır.

Tablo 3. Özdeğerler ve Varyanslara İlişkin Yüzdelik Tablosu

\begin{tabular}{ccccc}
\hline Faktörler & $\begin{array}{c}\text { Özdeğer } \\
\%\end{array}$ & $\begin{array}{c}\text { Açıladığ } \\
\text { Varyans } \\
\%\end{array}$ & $\begin{array}{c}\text { Yığışımlı Öz- } \\
\text { değer } \\
\%\end{array}$ & $\begin{array}{c}\text { Yığ1şımlı } \\
\text { Varyans } \\
\%\end{array}$ \\
\hline 1 & 12.21642 & 25.99238 & 12.21642 & 25.99238 \\
2 & 4.97605 & 10.58735 & 17.19247 & 36.57972 \\
3 & 4.28498 & 9.11698 & 21.47745 & 45.69670 \\
\hline
\end{tabular}

Tabloya bağlı olarak bu ölçek ile ölçülmeye çalışılan ABBT' ndeki geleneksel bilgi, magazinsel bilgi ve bilimsel bilgi faktörlerinde meydana gelen değişikliklerin \% 45' inin bu ölçek ile ortaya koyulabildiği görülmektedir.

ABBT Deneme Formu' ndaki 2., 3., 4., $\quad$ 5., 6., 7., 8., 9., 10., 11., 12., 13., 15., 17., 20., 21., 22., 23., 24., 25. 26., 27., 28., 29., 30., 31., 32., 37., 38., 39., 40., 41., 44., 45., 46., 47., 48., 49., 50., 51., 53., 56., 58., 62., 63., 67. ve 69. maddeler (toplam 47 madde olarak Tablo 1' de sıralanmış olan maddeler) son ölçeği oluşturan maddelerdir. 
Bu maddelerden oluşan nihai ölçeğin güvenilirlik katsayısı (KR-20 güvenilirlik katsayısı) 0,93 olarak bulunmuştur. Öyle görünmektedir ki ölçek bu haliyle çok yüksek bir iç tutarlılık göstermektedir. Bu anlamıla da güvenilirliği oldukça yüksektir.

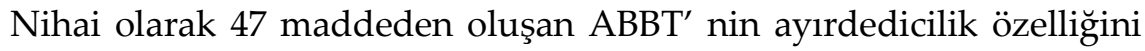
görebilmek için deney ve kontrol grupları oluşturulmuştur.

Deney grubu, Kayseri Varoluş Psikolojik Danışmanlık Merkezi bünyesinde açllan Ana- Baba Okulu programına katılan (dolayısıyla ölçek içeriğindeki bilgileri edinmiş olan), toplam 25 ana-babadan oluşmaktadır.

Kontrol grubu ise, Erciyes Üniversitesi çalışanları, Kayseri Nuh Mehmet Baldöktü Anadolu Lisesi çalışanları ve Kayseri Özel Özgün Anaokulu öğrenci velileri arasından, deney grubunda yer alan ana-babaların özelliklerine benzerlik gösteren ve random olarak seçilmiş 25 kişiden oluşmaktadır.

Ölçek, deney ve kontrol grubuna 21 gün ara ile iki kez uygulanarak, test-tekrar test yöntemiyle; deney ve kontrol gruplarının kendi içlerindeki değişimleri gözleyebilmek amacıyla ön test ve son test puanları tekrarlı ölçümler için t testi ile karşılaştırılmış ve sonuçlar Tablo 4, tablo 5 ve tablo 6 ' da gösterilmiştir.

Tablo 4. Deney Grubunun Öntest-Sontest Puanlarının Karşılaştırılması

\begin{tabular}{lrrrrrr}
\hline Ölçüm & $\mathrm{N}$ & $\bar{X}$ & $\mathrm{~s}$ & $\mathrm{sd}$ & $\mathrm{t}$ & $\mathrm{p}$ \\
\hline Ön & 25 & 46,16 & 0,94 & 24 & 2,28 & $0,032^{*}$ \\
Son & 25 & 46,44 & 0,71 & & & \\
\hline
\end{tabular}

${ }^{*} \mathrm{p}<0,05$

Deney grubunun puanlarında işlem öncesinden işlem sonrasına ufak bir yükselme gözlenmiştir. Deney grubunun ön testteki yanıtlarına oranla son testte, anlamlılık düzeyinde daha tutarlı yanıtlar verdiği görülmektedir.

Tablo 5. Kontrol Grubunun Ön test -Son test Puanlarının Karşılaştırılması

\begin{tabular}{lcccccc}
\hline Ölçüm & $\mathrm{N}$ & $\bar{X}$ & $\mathrm{~s}$ & $\mathrm{sd}$ & $\mathrm{t}$ & $\mathrm{p}$ \\
\hline Ön & 25 & 12,56 & 5,22 & 24 & 0,16 & 0,877 \\
Son & 25 & 12,48 & 4,46 & & & \\
\hline
\end{tabular}

$\mathrm{P}>0,05$ 
Kontrol grubunun ölçek puanları ortalamaları, işlem öncesinden işlem sonrasına istatistiksel olarak anlamlı bir değişim göstermemiştir. Buna göre kontrol grubu değişmeden kalmıştır.

Tablo 6. Ölçeğin Deney ve Kontrol Gruplarını Sontest Puanlarına Göre Ayırt Etme Gücü İçin $\mathbf{t}$ Testi

\begin{tabular}{lcccccc}
\hline Ölçüm & $\mathrm{N}$ & $\bar{X}$ & $\mathrm{~s}$ & $\mathrm{sd}$ & $\mathrm{t}$ & $\mathrm{p}$ \\
\hline Deney & 25 & 46,16 & 0,94 & 26 & $-36,90$ & $0,000^{*}$ \\
Son & 25 & 12,48 & 4,46 & & & \\
\hline
\end{tabular}

${ }^{*} \mathrm{p}<0,05$

Tablodan da okunabileceği gibi deney ve kontrol gruplarının sontest puanları ortalamaları arasında istatistiksel olarak anlamlı bir fark bulunmaktadır.

\section{Sonuç}

Doğumla birlikte, gerek 0-2 yaş dönemini içeren bebeklik dönemindeki bebeklerde, gerek çocukluk dönemindeki (6-11/13 yaş) çocuklarda gerekse ergenlik dönemindeki (11/13-19/21 yaş) ergenlerde görülebilen davranışsal ya da ruhsal bozuklukların (fizyolojik nedenler dışında) en temel nedeninin anne baba tutumları olduğu bilinmektedir. Bu gerçek, kuramsal olarak Psikoseksüel Gelişim Kuramı'nda, Psikososyal Gelişim Kuramı'nda, Bağlanma Kuramı'nda özellikle vurgulanmıştır. Yanısıra kuramlardan hareketle günümüze kadar, anne baba tutumlariyla ilişkilendirilerek yapılmış sayısız araştırmalarla da ortaya konmuştur. Sağlıklı anne baba tutumları oranının yükseltilmesinin de sağlıksız anne baba tutumlarının sağlıklı tutumlara dönüştürülmesinin de en etkin yolu olarak anne babalara bilimsel bilgiler kazandırarak bilişlerini değiştirmek gerektiği, çünkü tutumun değişmesinde en önemli bileşenin bilgi olduğu vurgulanmaktadir.

Bu bağlamda, anne babaların çocuk yetiştirmeye ilişkin var olan tutumlarının (özellikle sağlıksız tutumlarının) gerisindeki bilişsel yapılarındaki bilgilerin tespit edilmesi büyük önem taşımaktadır. Bu bilgilerin ne tür bilgiler olduğu doğru bir biçimde yani geçerliliği ve güvenilirliği olan 
bir ölçek aracılığıyla belirlenebilirse, hangi bilgilerde değişime gidileceği ve ne tür bir çalışma yapılacağ 1 da planlanmış olacaktır. Yani anne babaların bebeklik, çocukluk ve ergenlik hakkında ne bildiklerinin, bu bilgilerinin ne tür bilgiler olduğunun, bilgilerinin düzeylerinin (özellikle bilimsel temelli olmayan bilgilerinin) bilinmesi, tutumlarını, sağlıklı yönde düzenleyebilmek için gereklidir.

Bunlardan hareketle, anne babaların, bebeklikten itibaren ergenlik dönemi sonuna kadar çocuk yetiştirmeye ilişkin tutumlarının gerisindeki anne babalık bilgilerini, bu bilgilerin türlerini içeren ve düzeylerini ölçebilen bir ölçme aracı (test) planlanmış ve oluşturulmuştur.

Geliştirilen ölçek, katılımcı sayısı ve demografik açıdan katılımcıların çeşitliliği bağlamında istatistiksel analizlerin gerektirdiği yeterliliktedir. Yapılan çalışmalar sonunda ölçeğin deney ve kontrol gruplarını son test puanlarına bağlı olarak ayırt edebildiği görülmüştür $(t=-36,90 ; p<0,01)$. Nihai olarak 47 maddeden oluşan ölçeğin güvenilirlik katsayısı da (KR-20 güvenilirlik katsayısı) 0,93 olarak bulunmuştur. Elde edilen değerlere bakıldığında; ölçek bu haliyle çok yüksek bir iç tutarlılık göstermektedir. $\mathrm{Bu}$ anlamıla da güvenilirliği oldukça yüksektir. Sonuç olarak, $\mathrm{ABBT}^{\prime}$ nin kabul edilir psikometrik özelliklere sahip olduğu görülmüştür.

Geliştirilen ABBT (Ana-babalık Bilg Testi)' nin bilimsel araştırmalarda ya da uygulamalı çalışmalarda kullanılmasıyla, sonuçlara dayalı sağlıklı ana-baba tutumlarının oluşmasına ve daha bilimsel ana-babalık bilgilerine sahip ana-babaların sayısını artırmasına katkıda bulunulabileceği düşünülmektedir.

Ayrıca geliş̧irilen ABBT ile ana-babaların, ana-babalık bilgi düzeyi' ni belirlemek olası olabilecektir ki bunun da ana-babalara yönelik çalışmalarda hangi alana ağırlık verileceğinin belirlenmesi bakımından büyük yarar sağlayabileceği düşünülmektedir. 


\section{EXTENDED ABSTRACT}

\section{Parenting Knowledge Test: Validity and Reliability Study \\ Halis Özerk \\ Arel University}

Philosophers have opined about builder nature of childhood; moralists have explained on the behavior of children; parents have wanted to understand the development of children. However, analyzing baby and child as separate entities from grown-ups started in the 16th century. It was also started to analyze parents' attitudes in babyhood, childhood and adolescence period by scrutinizing human behavior and personal characteristics. Endeavoring to associate these attitudes with the behavior of individuals has continued until today. However, remaining incapable of conscious parentage is seen in national and international research findings.

For Freud, founder of psychoanalytic theory, parents' attitudes have a great place in personality development and behaviors of individuals in the childhood period. As a matter of fact, he pointed out that being stuck in any of these periods because of improper attitudes of parents can determine personal characteristics of the individual (Öztürk,1989, p.62; Geçtan, 1993, p.43; Cüceloğlu, 1998, p.412,413). Adler de Jung who is known as the follower of psychoanalytic theory agreed on parents' attitudes play a significant role in the future life of children.

Bowlby, Ainsworth, Klein, and Harlow who are accepted as the leaders of attachment theory emphasized on the importance of touch, warm interest and communication style of a mother with her baby in babyhood; style of meeting the necessities of the baby. They also expressed that there may occur secure or problematic attachment in baby based on positive or negative attributes (Ainsworth, 1985, 1989; Ainsworth an Bell, 1970; Aikins, Howes and Halilton, 2009; Carver,1998, p.281-282; Brown and Wright, 2003; Robinson and Moss, 1970; Sevinç, 2016).

Belsky, Sligo, Jaffee, Woodward, and Silva (2005) conducted a study and found a significant relationship between the child-rearing style of mothers and child-rearing style of the parents of the same mothers. 
Relating to the subject, studies, especially in our country, reveal that parents feel incompetent in several topics about their children; they frequently have difficulties (Ulusavaş, 1988; Ataklı, 1999).

With reference to Hassoy and Çakıcı (2012), parents who have children with behavior disorders have not enough knowledge on behavioral deficits (tics, attention deficit, and hyperactivity, lying, enuresis, school phobia, stuttering, psychosomatics disorders, aggressiveness); therefore, they cannot distinguish normal behavior from behavioral disorders; accordingly, they display unhealthy attitudes.

It is expressed in social psychology in which attitude and attitude change are predominantly discussed that attitudes have three fundamental components as thought, emotion and behavior; the key fact that specifies the attitude change is the knowledge repertoire in cognitive structure (Kağıtçıbaşı, 2003, p.108). Accordingly, the first step to be changed the attitudes is to know what the knowledge of the person in his cognitive structure is.

Parental Knowledge (information) concept was developed by the investigator by being inspired by parents' attitudes theoreticians and researchers who survey the parents' attitudes; it was also used in this study.

The purpose of this study was to develop a scale that can determine the types and levels of knowledge behind parents' attitudes; performing the validity and reliability studies of the related scale was the goal as well. Parental Knowledge Test (PKT) is divided into 4 main categories in principle as prenatal, babyhood, childhood and puberty; entirely 100 expressions were selected from the item pool belongs to these categories. Scale trial form that consists of 70 expressions was prepared by evaluating the expressions with professionals; eliminating some expressions and also emending in some of the expressions. It was especially paid attention to information that was asked to parents to answer to be certain information based on a scientific basis. PAKT trial form whose guideline was also already prepared was applied in the research group (entirely 110 parents whose 45 were males and 65 were females) for validity, reliability and factor analysis study.

First of all, for item selection, each of the items was scrutinized by both biserial correlation coefficients and sub-super group discrimination to determine whether there is any distinctiveness in terms of item difficulty level and their correlation with a total point. The items whose distinctiveness coefficients got values under $0.30^{\prime}$ were eliminated at the end of item 
distinctiveness index and sub-super group distinctiveness calculations based on biserial correlation coefficients. Rest 52 items were inserted in factor analysis to specify the factor structure (basic dimensions) of the scale. Statistical 4.5 program computed tetrachoric correlation coefficients among the items; principal component analysis (factor analysis) based on tetrachoric correlations was conducted. It was seen at the end of the analysis that some of the items placed in both two factors at the same time; varimax rotation was performed to organize the factor structure. We observed as the result of related rotation that items of the scale are gathered on three key factors (dimensions). These three key factors that were specified by factor analysis of PAKT have been entitled as follows;

The 1st factor is "Traditional Knowledge"

The 2nd factor is "Magazinish Knowledge"

The 3rd factor is "Scientific Knowledge".

The final scale has been reached at the end of repeated factor analysis with rotation. The final scale is composed of 47 items. Experimental and control groups were established to see the distinctiveness feature of PAKT. The scale was applied in the experimental and control group for two times by a 21-days gap. Pretest and posttest scores were compared by t-test for repetitive measures on the purpose of observing the transformations in experimental and control groups in themselves. There is a statistically significant difference between posttest point averages of experimental and control groups. For this finding, the scale can distinguish the experimental and control groups based on the posttest scores $(t=-36,90 ; p<0,01)$. The reliability coefficient (KR-20reliability coefficient) of the final scale with these items was calculated as 0,93.

It would appear that this scale, as is, shows a so high internal consistency; accordingly, its reliability is pretty high as well. In conclusion, PAKT has reasonable psychometric attributes; it can be used in research and applications.

\section{Kaynakça / References}

Arkan, B. ve Üstün, B. (2009). Davranım bozukluğu olan çocuklara psikiyatrik yaklaşımda anne-baba eğitim programları: İki örnek bağlamında bir değerlendirme. Psikiyatride Güncel Yaklaşımlar, 1, 155-174. 
Aikins, J. W., Howes, C. ve Hamilton, C. (2009). Attachment stability and the emergence of unresolved representations during adolescence. Attachment and Human Development, 11(5), 491-512.

Ainsworth, M. D. S. (1985) Attachments across the life span. Bulletin of the New York Academy of Medicine, 61, 792-812.

Ainsworth, M. D. S. (1989). Attachments beyond infancy. American Psychologist, 44(4), 709-716.

Ainsworth, M. D. S. ve Bell, S. M. (1970). Attachment, exploration, and separation: Illustrated by the behavior of one-year-olds in a strange situation. Child Development, 41, 49-67.

Ataklı, A. (1999). Toplumsal kalkınma açısından ilköğretimde çocuğu olan ailelerin eğitim gereksinimleri. Kuram ve Uygulamada Eğitim Yönetimi, $18,245-255$.

Ay, F. ve Şahan, G. (2018). Aile eğitimi kurslarının yetişkin eğitimi bağlamında etkililiğinin değerlendirilmesi. Uşak Üniversitesi Sosyal Bilimler Dergisi, 11, 66-86.

Belsky, J., Sligo, J., Jaffee, S. R., Woodward, L. ve Silva, P. A. (2005). Intergenerational transmission of warm- sensitive- stimulating parenting: A prospective study of mothers and fathers of 3-year-olds. Child Development, 76(2), 384-396.

Brown L.S., ve Wright, J. (2003). The relationship between attachment strategies and psychopatology in adolesence. Psychology And Psychopato$\log y, 76,351-367$.

Carver, C., ve Scheier, M. (1998). Perspectives on psychology. Cambridge University Press, 281-282.

Çekiç, A., Akbaş, T. ve Hamamcı, Z. (2016). Akılcı duygusal aile eğitim programının anne babaların akılcı olmayan inançlarına ve anne babalik streslerine etkisi. International Journal of Human Sciences, 13 (1), 23982417.

Erol, N., ve Şimşek, Z., (1997). Türkiye ruh să̆lığı profili: Çocuk ve gençlerde ruh sağlığı: Yeterlik alanları, davranış ve duygusal sorunların dağılımı. N Erol, C Kılıç, M Ulusoy , M Keçeci ve Z Şimşek (eds). Ankara: Eksen Tanıtım Ltd. Şti., s:25-75.

Gander, M. J. ve Gardiner, H. W. (1981). Child and adolescent development. (Çev. Dönmez, A., Çelen, N. ve Onur, B. (1993). Çocuk ve ergen gelişimi. Ankara: İmge Yayınları. 
Gullo, F. D. (1988). A comparative study of adolescent and older mothers' knowledge of infant ağabeylities. Child Study Journal, 18(3), 223-231.

Hambleton, R. K., Swaminathan, H. ve Rogers, H. J, (1991). Fundamentals of ttem response theory. Sage Publications Inc.

Hassoy, P. ve Çakıcı, M. (2012). Çocuklarda görülen davranış bozuklukları ile ilgili ailelerin bilgi düzeyleri ve tutumları. Hacettepe Üniversitesi Ĕ̆itim Bilimleri Fakültesi Dergisi, 2(özel sayı), 01-14.

Kauffman, J.M. (1997). Characteristics of emotional and behavioral disorders of children and youth (sixth edition). New Jersey: Prentice - Hall.

Kazdin, A.E.(1987). Treatment of antisocial behavior in children: Current status and future directions. Psychological Bullettin, 102, 187-203.

Lally, J. R., Lerner, C. ve Hurvitz, E. L. (2001). National survey reveals gaps in the public's and parents' knowledge about early childhood development. Young Children, 56, 2, 49-53.

Lord, F. M. ve Novick, M. R. (1968). Statistical theories of mental test scores, Adison-Wesley Pub. Inc.

Nilsson, E. L. (2016). Parent's monitoring-relevant knowledge, involment with deviant peers and substance use: Time-variant and long-term associations among adolescents aged 12-17. International Journal of Social Science Studies, 4(10), 91-100.

Öztürk, O. (1989). Ruh sağllğı ve bozuklukları. İstanbul: Evrim yayınları.

Robinson J.P., ve Moss, H.A.(1970). Patterns and determinants of maternal attachment. Journal of Pediatrics, 77,976-985.

Sevinç, G. (2016). Güvenli bağlanma düzeyi ve benlik kurguları ile üniversiteye yeni başlayan öğrencilerin uyumu arasındaki ilişki. Yayımlanmamış Yüksek Lisans Tezi, Ankara Üniversitesi, Eğitim Bilimleri Enstitüsü, Ankara.

\section{Kaynakça Bilgisi / Citation Information}

Özerk, H. (2019). Anne babalık bilgi testi: Geçerlilik ve güvenilirlik çalışması. OPUS-Uluslararası Toplum Araştırmaları Dergisi, 13(19), 1784-1805. DOI: 10.26466/opus.594747 